\title{
The Incorporation Problem in Interdisciplinary Legal Research, Part 2: Case Studies
}

\author{
Sanne Taekema \& Wibren van der Burg*
}

As our previous issue 8:2, this issue of Erasmus Lam Reviem addresses the problem of incorporating insights from non-legal disciplines into legal research. The discussion of that problem in the introduction to issue $8: 2$ is therefore also the starting point for the current issue, and for a full understanding of the questions underlying the contributions to this issue, we refer the reader to that earlier introduction. ${ }^{1}$ Whereas the articles in issue 8:2 focused on more general and theoretical questions with regard to the incorporation problem, this issue contains a number of case studies. The first four articles reflect on concrete research projects conducted by legal researchers in which they include a form of interdisciplinarity. The final article takes a different approach, by using Ph.D. theses, scholarly articles, and Law Reform Commission reports, analyzing whether and how legal researchers do interdisciplinary research.

There are particular insights to be gained from a case study approach to the incorporation problem. The basic idea underlying the wish to include case studies here is that we need careful consideration of how incorporation works in the practice of legal research as test cases for the theoretical claims. Moreover, one of the main points of departure for our approach is that we need to assess the necessity of interdisciplinary legal research in light of the research question of the research at hand. If this idea holds, it is to be expected that there will be a great variety in modes of interdisciplinarity, depending on the precise topic and set-up of the research presented. This is certainly true of the current issue.

In addition to the particular research question, it is the broader embedding of that question in a particular approach to the field that seems of paramount importance. Some fields of research in which legal scholars engage are areas in which the boundaries between disciplines have become fluid. Researching problems in such areas, therefore, almost as a matter of course, involves elements from different disciplines. The articles by Annie de Roo and Andria Naudé Fourie provide examples.

Annie de Roo describes four multidisciplinary projects in which she has been involved. The central theme con-

* Sanne Taekema and Wibren van der Burg are Professor of Jurisprudence and Professor of Legal Philosophy and Jurisprudence, respectively, at the Erasmus School of Law in Rotterdam.

1. S. Taekema and W. van der Burg, 'The Incorporation Problem in Interdisciplinary Legal Research, Part 1: Theoretical Discussions', 8(2) Erasmus Law Review 39-42 (2015), doi: 10.5553/ELR.000050. necting all projects was human conflict strategies and governance. She discusses in rich detail various aspects of executing broad projects alike these. When analysing how legal practice and scholarship have incorporated the insights from conflict management studies, she suggests that these insights are frequently 'cannibalised' in legal doctrinal research, as only those findings are incorporated that can be translated into doctrinal legal concepts. In addition, she advocates a 'reverse incorporation': empirical conflict management studies might profit from taking legal doctrinal research more seriously as, exactly because of its normative stance, it has something crucial to add to the empirical data.

Andria Naudé Fourie gives an account of how legal doctrinal insights figure in quantitative empirical research on international accountability mechanisms at development banks. These mechanisms, most prominently the complaint procedure at the World Bank Inspection Panel, need to be studied from an interdisciplinary angle. In order to facilitate such research she has made a database of cases generated by these mechanisms. In the article, she shows how legal doctrinal methods have figured in her design and construction of the database and in the analysis of the cases. Employing legal doctrinal concepts thus furthers understanding of accountability mechanisms that are concerned with the intersection of economic, social, environmental, and legal concerns. In turn, the study of such mechanisms on the basis of a comprehensive database of cases shows patterns of legal development in a context that blurs the boundaries between formal law and informal normativity.

The articles of Henrard and Kloosterhuis present two ways of engaging directly with the need of how to integrate findings from another discipline: Henrard's is an internal approach in which a doctrinal argument encounters its limits and requires input from other disciplines, whereas the more external approach by Kloosterhuis is based on the hypothesis that argumentation theory can provide a fruitful alternative explanation that can be used in doctrinal research.

Henrard's subject is the protection of minorities' rights by the European Court of Human Rights. She argues that the Court in several respects fails to properly balance all relevant interests and variables. One cause of this may be lack of knowledge, the other concerns about its own political legitimacy. The lack of knowledge could be remedied by relying on non-legal disciplines. Moreover, she argues that the more explicit and transparent inclusion of other disciplines could also have 
indirect beneficial effects for the political legitimacy of the Court.

Kloosterhuis focuses on the criminal act of insulting. He argues that there are various difficulties in interpreting the Dutch statutory norms about insulting; because of the vagueness, Dutch case law is uncertain and has even absurd consequences. According to Kloosterhuis, a standard doctrinal approach to insulting is inadequate to address these difficulties. Speech act theory, however, can provide a more precise understanding of the concept of insulting.

The final article includes a different type of case study, namely a descriptive analysis of whether and how legal researchers do interdisciplinary research. Terry Hutchinson focuses on one specific type of research, namely research directed to law reform. She makes an extensive quantitative analysis of Australian Ph.D. theses and articles written for Australian law journals. The conclusion is that most Ph.D. theses and law articles contain recommendations for reform and that there is a frequent use of interdisciplinary methods - even if doctrinal methods remain at the core of most studies. Furthermore, she discusses the work of the Australian Law Reform Commission, an institution that might be expected to include various types of non-disciplinary materials. However, she has to conclude that their reports do not provide much information about the extent to which non-doctrinal materials have been incorporated in the recommendations. 